\title{
NOTICIAS DE LIBROS $(*)$
}

Alan Cromartie: The Constitutionalist Revolution. An Essay on the History of England, 1450-1642, Cambridge University Press, Cambridge, 2006.

A nadie al que le interese, aunque sea sólo un poco, el fenómeno constitucional le pueden resultar ajenos los avatares de la historia del constitucionalismo inglés, país en el que se experimentaron tempranamente muchos de los cambios que caracterizan aquél. De ahí el interés del libro que comentaremos aquí, que es un intento de ilustrar, y de dar a conocer las claves, de un período en el que se produjeron unas transformaciones teóricas, y prácticas, que marcaron decisivamente la evolución de las instituciones británicas y, por consiguiente, las de una nación que se convertiría en modelo de respeto a las libertades y previsiones institucionales avanzadas, en un contexto en el que triunfaba el absolutismo más radical.

Cromartie hace un ejercicio de historia de las ideas —más bien podría decirse de las mentalidades y del pensamiento dominante- en el que, buceando en grandes cantidades de materiales publicados y en manuscritos, acaba por dibujar un panorama complejo, que sirve para explicar por qué frente a las pretensiones monárquicas de imponer regímenes similares a los del Continente, sentido en el que podían haber evolucionado perfectamente las instituciones inglesas, se alzó todo un entramado, también intelectual, que orientó las cosas en otro sentido, teniendo como primera consecuencia una cruenta guerra civil y, hecho entonces insólito, la decapitación de un Rey.

El libro se abre, tras una breve introducción, con una completa referencia a la obra de Fortescue, «Chief Justice» (Presidente) de uno de los más importantes tribunales ingleses («King's Bench») durante veinte años (1442-1461) del reinado de Enrique VI. En el capítulo correspondiente se reflexiona sobre la cultura jurídica inglesa de finales de la edad media, y principios de la moderna, y cómo en la misma se fue desarrollan-

(*) Sección coordinada por Francisco Javier Matia Portilla. 


\section{RESEÑA BIBLIOGRÁFICA}

do, poco a poco, la idea de una monarquía limitada por las leyes, antes de entrar en el análisis de los escritos de este autor, en los que se resalta que lo que le obsesionaba no era tanto que el Rey debiera obtener el consentimiento de los gobernados, sino que actuara siempre tras haberse aconsejado suficientemente (pág. 28). Esto se presentaba como una obligación de los monarcas, y aquí Cromartie resalta que Fortescue, frente a lo que defendieron interpretaciones posteriores de sus escritos, estaba lejos de alinearse con lo que podría llamarse «populismo», puesto que no dejó de mostrarse respetuoso con las prerrogativas regias.

En el segundo apartado el objeto principal son las publicaciones de Christopher $\mathrm{St}$ German. Al hilo de los acontecimientos que se desarrollaron en el reinado de Enrique VII se examina a fondo el Diálogo entre un doctor en teología y un estudiante del derecho inglés que elaboró este autor (1528) en el que destaca la centralidad que se le otorga a la costumbre, hasta el punto de equipararla a las leyes propiamente dichas ( «Statutes»), y la idea, ciertamente novedosa, de que, si bien el Rey podía tener algunos poderes extralegales, era posible someter los mismos al derecho ordinario. Se encuentran aquí, por tanto, los primeros gérmenes del constitucionalismo propiamente dicho y de la monarquía limitada.

Dando un giro a la argumentación, en el capítulo tercero Cromartie se lanza a examinar las implicaciones de la Reforma para el sistema político, con referencias a numerosos autores de los que extrae la conclusión (pág. 73) que el surgir del parlamento como un órgano decisivo del sistema en el pensamiento político inglés no debe ser tratado como la expresión de una teoría sino, más bien, como el resultado de ajustes tácticos de políticos que tenían poco de visionarios. El resultado fue que Enrique VIII encontró difícil usar su parlamento con el objetivo de declarar sus poderes reales sin también, simultáneamente, reconocer de manera implícita que dicha asamblea tenía el derecho de limitarlos o extenderlos.

El capítulo cuarto («Commonwealth and common law») continúa en la línea de examinar cómo evolucionó en Inglaterra la manera de entender el derecho y sus relaciones con los poderes reales. Partiendo de una situación en la que todas las normas tenían procedencia real, y en la que nadie ponía en cuestión los poderes extralegales del monarca, poco a poco se fue imponiendo la idea de que el common law venía siendo creado por el pueblo, de modo que el consentimiento de este fue apareciendo como criterio principal de legitimidad. Repasa Cromartie la obra de diferentes autores de la época que fueron construyendo paulatinamente principios que podrían calificarse de protoconstitucionales.

En el siguiente apartado se analizan las relaciones entre puritanos y anglicanos, resaltando en primer lugar la supervivencia del aparato de la Iglesia, y como la misma facilitó el surgimiento de la estructura intelectual del pensamiento constitucional inglés. Se destaca la obra de Richard Hooker (1554-1600), en el sentido de que logró integrar en el anglicanismo las ideas que propugnaban un derecho basado en el consentimiento de los gobernados.

El pensamiento inglés en la época de Jacobo I es el objeto del siguiente capítulo, en el que se analiza en primer lugar el del mismo rey, que aparece como mucho más 


\section{RESEÑA BIBLIOGRÁFICA}

complejo que el de la supuesta adscripción al absolutismo más rancio que ha sido habitual en quienes han examinado el mismo. Se ve como, sin embargo, decidió apoyar la facción más conservadora del episcopado. Pero fue precisamente en su reinado en el que tuvo lugar la explosión del interés por el sistema jurídico, tal y como estudia Cromartie en el capítulo 7, explosión que conduciría al surgimiento de la política constitucionalizada, puesto que empezó a pensarse en el common law como una costumbre general, creada por el pueblo, en una manera de ver las cosas útil para limitar los poderes del monarca. De nuevo analiza el autor el pensamiento de diversos publicistas de la época, subrayando como en ese período se reafirman los poderes del parlamento para enjuiciar como ilegal el comportamiento inadecuado de los reyes, de modo que la idea de que éste puede declarar derechos, enjuiciar el derecho, e incluso anular acciones de aquellos, se convirtió en uno de los factores más significativos de la política inglesa. Se detiene especialmente en la figura de Sir Edward Coke (1552-1634) para acabar resaltando como paulatinamente, por el desarrollo de diversas polémicas sobre los poderes reales, el common law fue afirmándose como la única fuente de legitimidad.

El capítulo final tiene el mismo título que el libro («The constitutionalist revolution»). En el mismo resalta Cromartie que lo que cambió en el período histórico examinado no fue el comportamiento de los poderes públicos sino la cultura política en la que estos operaban, caracterizada por el ascenso imparable del common law. En ese contexto fue especialmente torpe la política de Carlos I, con su insistencia en la prerrogativa real de exigir impuestos y otras exacciones al margen del parlamento, y su inadecuada política religiosa, en la que se detiene especialmente el autor, con un análisis de las actividades del arzobispo Laud, una de las figuras de importancia en esta época. Critica, sin embargo, Cromartie la tendencia a sobrevalorar los fenómenos religiosos como base de los conflictos, y se ocupa de diversos autores que teorizan sobre la supremacía parlamentaria, y la necesidad del sometimiento al derecho de todos los poderes públicos, llegando incluso a planteamientos republicanos. Nos hallamos ante un «triunfo de los juristas» (pág. 274), que nos recuerda que «cuando la política es absorbida dentro de un sistema de derecho positivo, los métodos y prioridades de ese sistema inevitablemente condicionan la substancia y el lenguaje del debate político» (pág. 274). Se impuso una concepción de las cosas en la que los poderes públicos aparecían al servicio de las libertades, de modo que los derechos debían estructurar el orden social.

El libro se cierra con un epílogo sobre el constitucionalismo de John Locke, en el que se afirma que este autor dio un relato filosófico de las expectativas de los constitucionalistas, y, en particular, encontró un nuevo medio de justificar el lema establecido de que la protección de la vida, la libertad y los bienes era el principal objetivo de todo orden legal. Pero también no le cabe duda a Cromartie de que si Locke tenía mucha más confianza que ninguno de sus precursores en que el contenido del derecho natural consistía en derechos del tipo de la propiedad, debía la misma a una tradición que creía que el poder legítimo era esencialmente judicial.

Dada cuenta del contenido de la obra, conviene cerrar esta noticia con algunas reflexiones sobre sus características generales, y sobre su significado para la historia 


\section{RESEÑA BIBLIOGRÁFICA}

del constitucionalismo inglés. En primer lugar, hay que decir que nos hallamos ante un excelente trabajo académico, basado en la utilización a fondo, y adecuada, de fuentes primarias y secundarias. Está bien escrito y estructurado y, aunque pueda resultar en ocasiones algo premioso, no deja de resaltar bien sus tesis principales.

El contenido de las mismas es ciertamente importante, pues muestra como en el nivel de debate político, y de las expresiones jurídicas del mismo, las ideas fundamentales del constitucionalismo, que triunfarán definitivamente en la revolución gloriosa (1688), tienen sus raíces en desarrollos muy anteriores, que Cromartie ilustra con acierto. El período del que se ocupa es especialmente convulso, tanto en lo religioso como en lo político, y ha sido objeto en el pasado de análisis que el autor revisa con agudeza, sentando nuevas interpretaciones más matizadas de fenómenos históricos que repetidas veces se han estudiado desde perspectivas poco objetivas, más bien propagandísticas, de unas u otras posiciones.

La revisión que hace Cromartie de las ideas en boga de aquella época, y de las implicaciones de las mismas en el debate político, resulta sugerente y matizada. También es útil para adentrarse en un período de la historia inglesa que aparece como importante, y al que el autor reconoce la trascendencia que se merece. Como ya dijimos más arriba, los debates a los que se refiere no son ajenos a ningún constitucionalista, y es por ello por lo que estos trabajos tan detallados contribuyen sin duda a ilustrar los contenidos de una historia compleja, que está en la base de desarrollos posteriores en los que se apoya el Estado constitucional actual.

No nos queda, por tanto, sino recomendar su lectura a todos los interesados en la evolución del constitucionalismo, puesto que estas indagaciones en lo que podría denominarse prehistoria de este fenómeno contribuyen, sin duda, a aclarar muchos de las soluciones adoptadas más adelante. El adecuado tratamiento de los materiales que se presentan, materiales de sumo interés, hace de la obra de Cromartie un hito importante en la historiografía del período, y no sólo eso, sino también un libro muy útil para reflexionar sobre los orígenes de muchas de nuestras soluciones constitucionales.

Como impone el lema de la colección en la que se presenta («Ideas in context») nos hallamos ante mucho más que un libro de historia de las ideas, que no deja en ningún momento de relacionar las mismas con el contexto en el que se desarrollaron, señalando con acierto sus consecuencias para la historia de las instituciones. Esta relativamente nueva manera de abordar los problemas, que tiene su ejemplo más claro en la obra del editor general de la serie a la que nos hemos referido (Quentin Skinner) es sumamente útil para aquellos que no consideran la historia como un fin en sí misma, sino como una manera de comprender mejor los problemas del presente. En ese sentido el libro de Cromartie es ejemplar, puesto que el análisis que se hace, sin dejar de ser riguroso y centrado en el período que estudia, invita a explicarse adecuadamente por qué en el mismo se produjeron los debates que se produjeron y de qué modo los mismos condicionaron los que vinieron con posterioridad. Va mucho más allá, por tanto, de la mera reflexión sobre el pensamiento de estos u otros autores, para plantearse como el mismo se incardina en una historia general especialmente atormentada, y de la que es posible extraer muchas enseñanzas. 
RESEÑA BIBLIOGRÁFICA

No se perderá el tiempo, por tanto, dedicándolo a la lectura de esta obra, que es de indudable interés para todos aquellos que se dedican al oficio de constitucionalistas, independientemente de que se trate de un buen ejemplo de cómo un historiador puede ilustrar con viveza un período de la historia de Inglaterra en el que se pusieron las bases de lo que mucho tiempo después se consolidaría como Estado constitucional.Ignacio Torres Muro. 